perature causes obvious differences in the appearance of adults which can be used as guides to the "temperature history" of the pre-adult stages and the size of chromosome puffs produced can be correlated with the temperature at which the animal is kept.

Mr. I. R. H. Allan (Ministry of Agriculture, Fisheries and Food) chaired the final discussion on future developments. On the research side, Dr J. C. Peters (Water Resources Board) felt that more use would be made of ecological modelling techniques. $\mathrm{Mr}$ M. J. Bulleid (Central Electricity Generating Board) thought that the future prospects for using warm discharges in fish farming were good, and on the recreational side the stocking of lakes and rivers for fishing would increase. Several speakers emphasized the need for more work on fish behaviour in relation to power station intakes, particularly in estuaries.

This symposium was useful in showing the wide range of ecological and experimental approaches currently being used to study thermal effects and in bringing together the varied interests involved with water resources. Even if some differences in approach were not exactly resolved, the meeting certainly helped to crystallize them.

\section{CONGENITAL MALFORMATIONS \\ Teratologists United}

from a Correspondent

THE European Teratology Society was formed recently to promote research into the causes, prevention and management of congenital malformations. Its first meeting in University College, Cardiff, on April 14-16 included symposia on all three facets and attracted an attendance of 250 . The presence of clinicians, epidemiologists and experimental scientists at the same meeting was very encouraging, because teratology has been separated for too long into its component disciplines. If the society can keep the support of these various groups, it should make an important contribution to the quality of research in this area.

A symposium on the aetiology of human birth defects was addressed by a geneticist (Professor W. Lenz, Münster University), an epidemiologist (Dr I. Leck, University of Manchester) and an experimental teratologist (Dr J. G. Wilson, University of Cincinnati). The issues were spelled out clearly, but little new emerged. There is still almost nothing known about the causes of human congenital malformations, except for a small number attributable to known genetic or environmental factors. It is generally agreed that a genetic susceptibility plus some environmental triggers are necessary, but the relative importance of these two components is not known. Nor is it known what the relevant environmental stimuli might be, although nutritional factors are indicated by a number of lines of evidence. One new and interesting correlation, reported by Professor C. R. Lowe (University College, Cardiff), is between the softness of drinking water supplies and the incidence of central nervous system defects.

The second symposium examined the problems of screening drugs for potential teratogenic properties. The present procedures were outlined by Professor H. Tuchmann-Duplessis (University of Paris) and were then discussed from the points of view of the pharmaceutical industry (by Dr J. Grauwiler, Sandoz Ltd, Basle) and of the university research department (by Professor F. Beck, London Hospital Medical College). The session concluded with a lengthy discussion. There seemed to be general agreement that current screening methods reduce the danger of another thalidomide disaster, although some speakers clearly thought that the present regulations are over-cautious and are unnecessarily banning some valuable drugs. The variability of teratogenic response shown by different species was also stressed, and it was hotly contested whether testing in rats, mice and rabbits is adequate or whether primates should also be used. Advocates of using monkeys stress the similarity of the defects induced by thalidomide in man and the rhesus monkey and that rodents are refractory to the effects of this drug. But many research workers remain unconvinced by these arguments and point out that amethopterin is teratogenic in rodents and in human beings but is apparently not so in the rhesus monkey.

It is hard to see how this question will be settled, because the list of known human teratogens is small, and hopefully will remain so. It would seem wise to investigate the possible use of a non-rodent species in testing for teratogenesis, but at present there seems to be no compelling reason why primates should be the best choice.

\title{
Morphine and Neurotransmitter Release
}

MORPHINE is thought to act in the brain by reducing the release of acetylcholine (ACh) at cholinergic nerve terminals. An alternative mode of action could be a reduction of the sensitivity of the post-synaptic ACh receptors by occupation by the narcotic. The potency of morphine-like analgesics is known to be correlated with their potency in reducing $\mathrm{ACh}$ released at muscarinic sites in the gut. The more accessible neuromuscular (nicotinic) junction has been used extensively to study quantitatively cholinergic transmission and as a model for studying the action of central nervous system depressants.

In next Wednesday's Nature New Biology, Pinsky and Frederickson report that both morphine and its analgesic-antagonist, nalorphine, block supramaximally stimulated transmission at amphibian and mammalian neuromuscular junctions. Nalorphine was the more potent in reducing the nerveinduced twitch of amphibian sartorius muscle and it augmented a morphineinduced depression. The blocking action was increased by d-tubocurarine (d-TC) which competes with $\mathrm{ACh}$ at the receptors. Both drugs were effective in concentrations five hundred times greater than that known not to depress nerve conduction and had no effect, at ten times the neuromuscular blocking dose, on directly stimulated muscles denervated three weeks previously.

Recording from single end-plates of muscles paralysed with d-TC, the first small dose of morphine increased the end-plate potential (EPP), but subse- quent higher doses produced a graded depression of EPPs, again augmented by nalorphine which alone was also depressant. Because high concentrations of morphine are not curare-like on the frog rectus abdominis muscle, neuromuscular block is probably induced by impairing $\mathrm{ACh}$ release.

Similar effects were seen on the twitch response of the rat hemidiaphragm to phrenic nerve activity. The initial potentiation of the twitch occurred with lower concentrations of nalorphine and was more prominent and prolonged than with morphine. An anticholinesterase action is unlikely because morphine is more effective than nalorphine as an inhibitor of ACh esterase in the rat brain.

In a second article Frederickson and Pinsky report that morphine reversibly depressed $\mathrm{ACh}$ output during indirect tetanic stimulation of the frog muscle, and this narcotic also produced a leftward parallel shift of twitch and of tetanic fusion tension plotted against $\log$ (ACh release). This facilitation which occurred even when high concentrations of neostigmine were present suggests that morphine enhances the action of $\mathrm{ACh}$ at its receptors. Whether post-synaptic facilitation occurs at cholinergic synapses in the brain and could account for morphine withdrawal symptoms remains of course unanswered, but the authors intend to study other narcotics and their antagonists at the neuromuscular junction as a possible model of what may apply in the brain. 